\title{
Disaster Risk Reduction Including Climate Change Adaptation Over South Asia: Challenges and Ways Forward
}

\author{
Rajesh K. Mall ${ }^{1,2}$ Ravindra K. Srivastava ${ }^{1,2,3}$ - Tirthankar Banerjee ${ }^{1,2}$. \\ Om Prakash Mishra ${ }^{4} \cdot$ Diva Bhatt $^{1}$ - Geetika Sonkar ${ }^{1,2}$
}

Published online: 20 December 2018

(C) The Author(s) 2018

\begin{abstract}
South Asia is vulnerable to a variety of hydrometeorological hazards, which are often crossboundary in nature. Climate change is expected to influence many of these hazards. Thus, climate-related risks over South Asia make disaster risk reduction (DRR) and climate change adaptation (CCA) key policy goals. Recently there is an increasing consensus that DRR including CCA should be embedded in development planning. Disaster risk reduction including CCA has progressively gained importance in global governance. Across South Asia, however, such integration is only in a preliminary stage. This review was to assess the existing status and scope of DRR including CCA in development projects across South Asia, so that an effective and achievable deliberation may be made to regional policymakers. A total of 371 projects relevant to CCA and DRR were reviewed. The project inventory was diverse in nature with respect to location, scale, sectoral focus, and strategic importance. Bangladesh, India, and Bhutan were observed to be proactive in implementing DRR- and CCA-related projects. Meta-analysis of the project inventory suggests an urgent need for an individual and collaborative convergence of processes for DRR and CCA through policies, plans, strategies, and programs.
\end{abstract}

Rajesh K. Mall

mall_raj@rediffmail.com; rkmall@bhu.ac.in

1 Institute of Environment and Sustainable Development, Banaras Hindu University, Varanasi 221005, India

2 DST-Mahamana Centre of Excellence in Climate Change Research, Banaras Hindu University, Varanasi 221005, India

3 Ministry of Home Affairs, New Delhi 110001, India

4 Ministry of Earth Sciences, New Delhi 110003, India
Keywords Climate change $\cdot$ Climate change adaptation - Disaster risk reduction $\cdot$ SAARC $\cdot$ South Asia

\section{Introduction}

Climate-related disasters in the South Asian region are becoming more frequent, destructive, and costlier in terms of both economic and social impacts (UNISDR 2011; Bhatt et al. 2015). From 1900 to 2015, there has been a continuous increase in the number of climate-related disasters, peaking from 2000 to 2015 (EM-DAT 2016). Interestingly, the rate of mortality associated with such disasters has been considerably reduced in the current era, even though the number of people reportedly affected has been increased enormously. Entire South Asia is frequently exposed to severe climate-related disasters, a situation that has been further complicated by unprecedented population growth, reaching a massive 1.8 billion in 2018 and predicted to increase by another 800 million people by 2050 . The entire population is vulnerable to change in climate and extreme events because of the low level of institutional capabilities, economic vulnerability, and great dependence on climatesensitive resources (SAARC 2008; MHA 2011; Mall and Srivastava 2012). Climate-related vulnerabilities are exacerbated by low population resilience; most people survive on less than USD 1 a day (UNDP 2013). The extent of this stress is, however, highly uncertain because the magnitude of climate-related disasters is so variable. In addition, the rural population across South Asia still survives on agriculture, which is regarded as the principal employment opportunity of more than $60 \%$ of its population. More than half of the South Asian countries, particularly Afghanistan, Bangladesh, Bhutan, and Nepal, are classified as least 
developed countries as of March 2018 (United Nations 2018) and are grappling with various socioeconomic issues such as poverty, health, and education. Therefore, climaterelated environmental hazards and their impacts potentially have serious consequences over the entire region and should be addressed with specific considerations of unique regional geomorphology, culture, and socioeconomic structures.

Disaster risk reduction means reducing disaster-related risks through a systematic effort. Improved preparedness, reduction in individual exposure, reduced damage to property, proper management of land, and enhanced population resilience are the core objectives of DRR (UNISDR 2011). Climate change adaptation only refers to the adjustment in natural or human systems in response to actual or expected climatic stimuli or their effects, including regulating damages and exploiting possible beneficial opportunities (UNFCCC 2008; IPCC 2013). Both DRR and CCA have several similarities and represent similar policy goals, DRR is concerned with a widely known problem in the field of all environmental hazards and CCA with only emerging issues related to climate change-instigated environmental hazards. While these concerns have different origins, DRR deals with all environmental hazards including CCA, which by definition is about change in climate and largely through the common factors of weather and climate and through tools used to monitor, analyze, and address adverse consequences (Kelman et al. 2017). In addition to CCA, many states have been making efforts to institutionalize several practices relating to DRR to reduce regional vulnerability. In tune with this paradigm shift in disaster management, the focus has shifted to other components of DRR, such as preparedness, prevention, and mitigation. However, many DRR measures, particularly those related to hydrometeorological events such as drought-proofing, flood protection, cyclone warning and shelters, malaria eradication, resistant agriculture, mangrove conservation, saline embankment, and alternative livelihood development, have similarities to CCA measures in terms of their application.

Various researchers, practitioners, policymakers, and organizations focused on the similarities and differences between CCA and DRR, and on the process for integration (Kelman and Gaillard 2008; Alexander et al. 2013; Hasan et al. 2013; Mercer et al. 2014; Banwell et al. 2018; Brewer et al. 2018; Dias et al. 2018; Raza 2018; Vij et al. 2018; Xu et al. 2018; Zuccaro and Leone 2018). Suggestions of increases in the frequency, intensity, and severity of climate-related disasters call for better integration of DRR and CCA in order to reduce vulnerability and increase population resilience, especially over the South Asian region (Seidler et al. 2018). However, the integration of CCA and DRR policies is extremely challenging and therefore requires a proper framework to avoid duplication and to derive optimal benefits from scarce resources (Mall et al. 2006, 2011a). Recently there have been emphases on including CCA within DRR to make it a single comprehensive mechanism with multiple approaches (Kelman et al. 2009, 2017). Kelman and Gaillard (2008) also emphasized that by embedding CCA within DRR, it ensures a long-term perspective to achieve development goals, neither by distracting through politics of climate change nor by emphasizing a hazard-focused approach. Kelman et al. (2017) concluded that CCA sits as a subset within DRR.

To develop and promote regional peace, stability, integrity, economic prosperity, and increased cooperation in terms of economic, social, and technical issues, in 1985 all the South Asian countries (Afghanistan, Bangladesh, Bhutan, India, the Maldives, Nepal, Pakistan, and Sri Lanka) established an organization known as the South Asian Association for Regional Cooperation (SAARC). The entire region is vastly diverse both in term of geographical and cultural features, with almost 1.8 billion people (39\% of the Asian and $23 \%$ of the world's population) (Table 1). Throughout this article, climate- and disaster-related issues and DRR including CCA issues are discussed against the backdrop of SAARC countries. While it is recognized that South Asia is frequently associated with disasters, information regarding the proper governmental framework for implementation of CCA and DRR is extremely scarce. This article specifically discusses institutional developments among the SAARC member states and their policies and programs for DRR and CCA. Attempts have been made to identify the areas for prospective regional collaboration in DRR including CCA in terms of analogous geological and hydrometeorological conditions. In conclusion, a list of suggestions and recommendations has been included especially for the SAARC member states, to improve institutional mechanisms for different facets of preparedness, response, improving resilience, and mitigation.

\section{South Asia Vulnerability: Turning Hazard into Disaster}

The South Asian region is a hotspot for almost all types of climate-related disasters (Gaiha and Hill 2010; Mall et al. $2011 \mathrm{~b}$ ). The region represents $10 \%$ (186) of 1889 disasters that occurred globally between 2010 and 2015 (UNESCAP 2016). The most prominent disaster risks are associated with floods, earthquakes, landslides, droughts, and cyclones. From 1967 to 2006, of the 784 reported disasters that caused 0.80 million deaths, $50 \%$ of the deaths were caused by floods and 25\% by cyclones (MHA 2011). 
Table 1 Human development indicators of the South Asian Association for Regional Cooperation (SAARC) member states. Source: UNDP (2013), UNISDR/SDMC (2014)

\begin{tabular}{|c|c|c|c|c|c|c|c|c|c|}
\hline \multirow{2}{*}{$\begin{array}{l}\text { SAARC } \\
\text { member } \\
\text { states }\end{array}$} & \multicolumn{2}{|c|}{$\begin{array}{l}\text { Population } \\
\text { (Millions) }\end{array}$} & \multirow[t]{2}{*}{$\begin{array}{l}\text { GDP ( } 2005 \\
\text { PPP \$ Billion) }\end{array}$} & \multirow[t]{2}{*}{$\begin{array}{l}\text { GDP per capita } \\
\text { (2005 PPP \$) }\end{array}$} & \multirow[t]{2}{*}{$\begin{array}{l}\text { HDI } \\
\text { rank }\end{array}$} & \multirow[t]{2}{*}{$\begin{array}{l}\text { Poverty } \\
\text { line* }(\%)\end{array}$} & \multirow{2}{*}{$\begin{array}{l}\text { Land area } \\
\text { (Thousand } \\
\mathrm{km}^{2} \text { ) }\end{array}$} & \multirow[t]{2}{*}{$\begin{array}{l}\text { Forest area (\% of } \\
\text { total land area) }\end{array}$} & \multirow[t]{2}{*}{$\begin{array}{l}\text { Agricultural land } \\
\text { (\% of total land) }\end{array}$} \\
\hline & 2012 & 2030 & & & & & & & \\
\hline Afghanistan & 33.4 & 53.3 & $37.2^{\mathrm{a}}$ & $1083^{\mathrm{a}}$ & 175 & - & 652 & 2.1 & 58.1 \\
\hline Bangladesh & 152.4 & 181.9 & 236.0 & 1568 & 146 & 43.3 & 130 & 11.1 & 70.3 \\
\hline Bhutan & 0.8 & 0.9 & 3.8 & 5096 & 140 & 10.2 & 47 & 69.1 & 13.2 \\
\hline India & 1258.4 & 1523.5 & 3976.5 & 3203 & 136 & 32.7 & 3287 & 23.7 & 60.5 \\
\hline Maldives & 0.3 & 0.4 & 2.5 & 7834 & 104 & - & 0.3 & 3.0 & 26.7 \\
\hline Nepal & 31.0 & 39.9 & 33.6 & 1102 & 157 & 24.8 & 147 & 25.4 & 29.6 \\
\hline Pakistan & 180.0 & 234.4 & 428.4 & 2424 & 146 & 21.0 & 796 & 2.2 & 34.1 \\
\hline Sri Lanka & 21.2 & 23.1 & 102.9 & 4929 & 92 & $7.0^{\mathrm{b}}$ & 65.6 & 28.8 & 41.6 \\
\hline Total & 1753.0 & 2141.8 & 5586.1 & 3241 & - & - & 5124.9 & 14.5 & 33.9 \\
\hline
\end{tabular}

*Poverty: Percentage of population living below international poverty line USD 1.25 per day (Data of India and Sri Lanka: 2002-2006, the rest are from 2001-2007)

${ }^{\mathrm{a}}$ Refers to 2010

bower bound estimate. Population of 2030: Estimated. HDI UNDP Human Development Index, 2012. PPP Purchasing Power Parity rate

Floods and droughts combined were reported to affect over 2 billion people, while cyclones were responsible for approximately 0.5 million deaths. Disaster-incurred economic loss was about USD 80 billion, with floods alone causing about USD 49 billion in losses (Gupta and Murlikrishna 2010). In the decade between 2005 and 2014, the trend was almost identical, with disaster being responsible for 1.2 million deaths in Southwestern and South Asia, representing almost $21.2 \%$ of all global deaths and economic losses of USD 80 billion in 2005 value (UNESCAP 2016).

Some SAARC member states with smaller geographic areas suffer from a large number of disaster events, and the populations' sensitivity, exposure, and socioeconomic resilience are the factors that ultimately determine the extent of the damage. A major threat to some of the countries adjoining the Himalayas and Central Asia comes from the fast-melting glaciers, which are projected to influence regional downstream runoff (IPCC 2013). However, in recent years through proper implementation of early warning systems, improved preparedness, exposure reduction, and efficient management plan there has been a reduction in damages particularly by hydrometeorological hazards. This essentially indicates that any disaster is possibly an interface between an extreme physical phenomenon (be it natural or anthropogenic) and human population, and it is actually the extent of population vulnerability that transforms a hazard to a disaster, not directly the nature itself (O'Keefe et al. 1976). The extent of impact from disaster depends on multiple interlinked factors, such as severity of the event; the nature of the community; preparedness for the event; exposure of the population; and the active geological, seismological, and hydrometeorological regimes of the region.

\section{SAARC: Evolution of Institutional Setup for Disaster Risk Reduction and Climate Change Adaptation}

This article focuses on the evolution and integration of institutional setup for DRR and CCA in eight SAARC member states over South Asia-Afghanistan, Bangladesh, Bhutan, India, The Maldives, Nepal, Pakistan, and Sri Lanka. The institutional setup of DRR and CCA was initialized only after the adoption of the Hyogo Framework for Action (HFA) and was further driven by the adoption of various international conventions (Fig. 1). The HFA was a first 10 years plan (2005-2015) to explain the necessity for developing resilience of nations and communities to reduce disaster losses, and provided guiding principles and practical means to achieve these. The Sendai Framework for Disaster Risk Reduction 2015-2030 (UNISDR 2015) is the recent successor instrument to the HFA and the first major agreement of the post-2015 development agenda. Globally, efforts for institutionalizing DRR and CCA have been mostly independent, as evidenced in the evolution of institutional structures, legislations, and policies for DRR and CCA. Efforts have therefore been made to understand the process of such evolution and recognize any attempts at possible DRR including CCA within the South Asian context. 


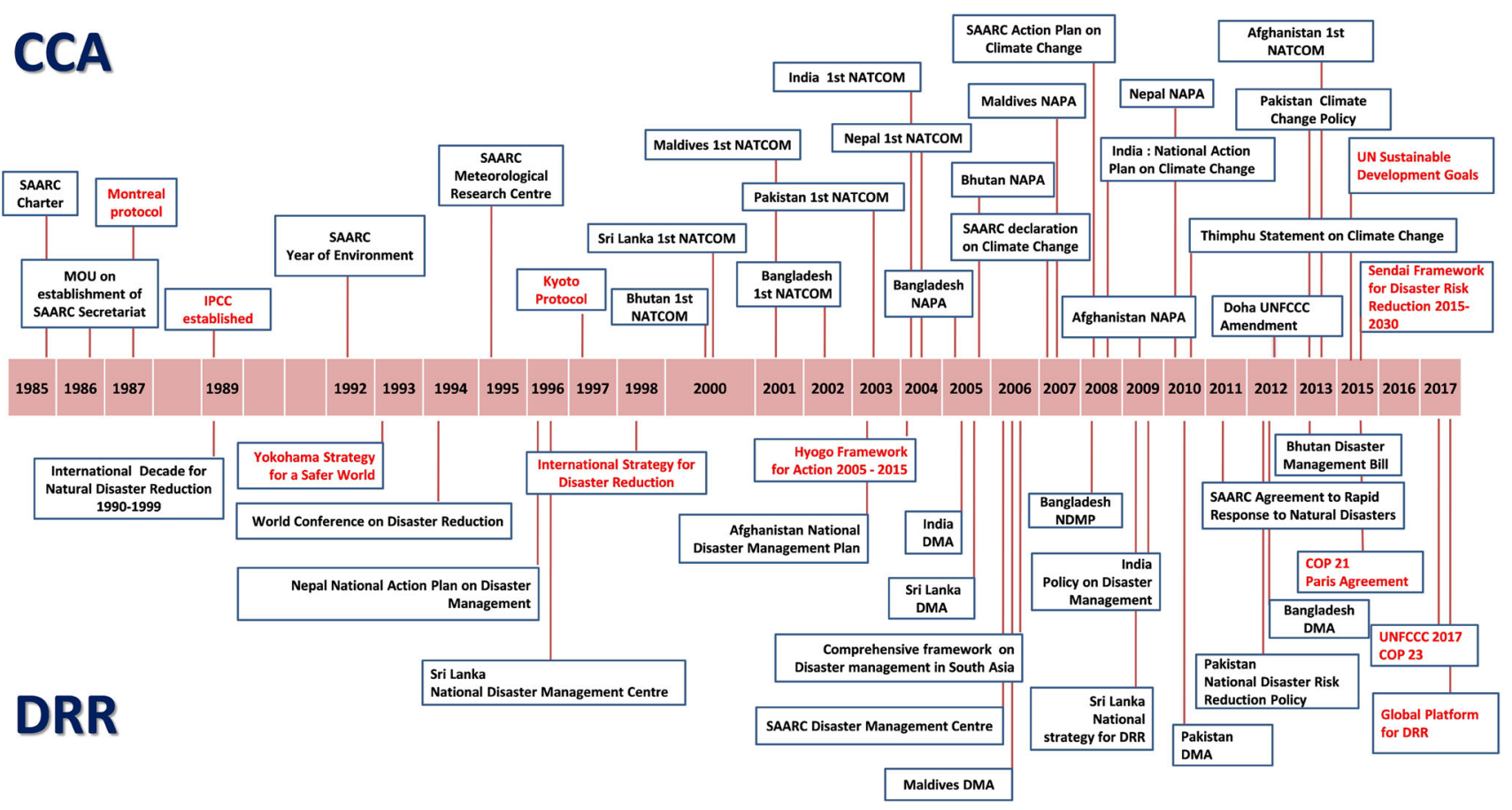

Fig. 1 Time series for development of major approaches, legislations, and institutions for climate change adaptation (CCA) and disaster risk reduction (DRR) in South Asia. Note: Boxes with red font colour indicate conventions/treaties with international significance

\subsection{Afghanistan}

The foundation of an institutional structure for disaster management in Afghanistan may be traced back to 1972, when a series of disasters hit the country (GIRA 2005). The Afghanistan National Disaster Management Authority (ANDMA), initially established in 1971 as the office of disaster preparedness, underwent several relocations within the Afghan government because of political disturbances before being upgraded to a ministerial level. It has a mandate to carry out mitigation, preparedness, response, and search and rescue operations followed by recovery and rehabilitation. The National Disaster Management Plan was further implemented in 2003, and in 2005, Afghanistan adopted the HFA. Since 2010, the United Nations Development Programme (UNDP) has led a national disaster management project to enhance institutional capacities at the national and provincial levels.

To address the issue of climate change, Afghanistan started with the National Development Framework, which was approved in 2002. The National Environmental Protection Agency (NEPA) was established in 2005 with a mandate to formulate environment-related policy, coordination, and enforcement and to work as a regulatory institution. In addition to the NEPA, the Ministry of Irrigation, Water Resources and Environment (MIWRE) has a mandate for environmental protection. The National Adaptation Programme of Action (NAPA) for Climate
Change was adopted in 2009 to address the issues of adaptation and mitigation, integration of climate change considerations into national planning, creating awareness, and developing societal resilience in response to climatic threats.

\subsection{Bangladesh}

The evolution of the institutional setup for disaster management in India, Bangladesh, and Pakistan may be traced back to the precolonial period, when it was an activitybased reactive mechanism. Over time, it was institutionalized as a proactive structure from a single-faculty domain to a multiple stakeholder setup with a modified focus on reducing and mitigating risk. In Bangladesh, the institutionalization of DRR was initiated with the Standing Orders on Disaster (SOD) in 1997 under the Ministry of Relief and Rehabilitation (MoR \& R), which assigns responsibilities to the various committees, ministries, and organizations (MoEF, GoB 2009, 2012). The MoR \& R was renamed the Ministry of Food and Disaster Management (MoFDM) in 2003 and was given responsibility for all functions related to DRR. The National Disaster Management Council (NDMC) and the Inter-ministerial Disaster Management Coordination Committee (IMD MCC) further coordinate DRR activities at the national level. Bangladesh now has a robust framework for disaster management, with legal backup from the Disaster 
Management Act of 2012; the National Disaster Management Policy, drafted in 2008; and the National Plan for Disaster Management of 2010. Additionally, the government of Bangladesh has specific national nodal agencies to address individual hazards for more efficient disaster management (MoEF, GoB 2012).

Bangladesh's vulnerability to climate change is attributed to various hydrometeorological and socioeconomic factors. The Ministry of Environment and Forests (MoEF) is the focal ministry for addressing and coordinating all climate change-related issues in coordination with the National Environmental Council, the National Steering Committee on Climate Change, climate change cells in all ministries, and the Climate Change Secretariat. The MoEF launched the NAPA in 2005 to build the capacity, coordinated action, and resilience of the country in response to climate change.

\subsection{Bhutan}

The national focal point for disaster management in Bhutan is the Ministry of Home and Cultural Affairs (MoHCA). Under the MoHCA, the Department of Disaster Management (DDM) was created in 2007 with a mandate to promote support and facilitate disaster management. The DDM has three divisions: preparedness and response, risk prevention and reduction, and rehabilitation and reconstruction. The National Committee for Disaster Management (NCDM) is the highest-ranking executive body for disaster management in Bhutan. The National Disaster Management Framework was published in 2006, and the Disaster Management Act was formally adopted in 2013.

Bhutan has severe risks associated with glacial lake outburst floods (GLOFs), flash floods, and landslides. Under its CCA program, Bhutan has undertaken several projects such as planning for emergency, contingent planning for vulnerable communities, rainwater harvesting, and GLOF risk mitigation. Following the ratification of the United Nations Framework Convention on Climate Change (UNFCCC) in 1995, Bhutan prepared its National Environment Strategy. Bhutan launched NAPA in 2006 with the support of the Danish government. The NAPA has a list of activities for enhancing the adaptive capacity of the country in response to the adverse effects of climate change.

\subsection{India}

Disaster management in India has evolved from a reliefbased approach to a multidimensional, proactive institutionalized setup with multiple stakeholders (MoEF 2012). Initially, activities to address natural hazards were kept within the purview of provincial and state agencies. During the 1990s, the Natural Disaster Management (NDM) division was created within the Ministry of Agriculture. However, following a series of disasters such as the Latur (1993), Malpa (1994), and Bhuj earthquakes (2001) and the Orissa super cyclone (1999), a systematic and comprehensive approach for disaster management was initiated, and the NDM was transferred in 2002 to the Ministry of Home Affairs. Further, a legal framework was created through the Disaster Management Act of 2005, which provided a mechanism for coordinated actions of response, preparedness, and mitigation at the national, state, and district levels. The National Disaster Response Force was also created for response and a National Institute of Disaster Management for capacity development.

Focused action on CCA came with the ratification of various international treaties and conventions, most notably the Vienna Convention in 1993, the Montreal Protocol in 1992, the UNFCCC in 1993, the Kyoto Protocol in 1997, and the Paris Climate Change Agreement in 2015. Further, several acts and policy measures have been implemented to regulate and mainstream environmental and climate-related issues. The Ministry of Environment, Forest and Climate Change (MoEFCC) is the nodal ministry for all climate change-related activities within the country. The Prime Minister's Council on Climate Change was created in 2008 to coordinate national actions for assessment of, adaptation to, and investigation of climate change. The National Action Plan on Climate Change (NAPCC) was launched in 2008 (MoEFCC 2008) to address various core issues of sustainable energy, energy efficiency, habitat, water, the Himalayan ecosystem, a green India, agriculture, and strategic knowledge.

\subsection{The Maldives}

The Maldives, an archipelago of low-lying coral islands located in the Indian Ocean, has gradually shifted its strategy from disaster relief to disaster preparedness. After ratifying the Kyoto Protocol in 1998 and adopting the action plan of the UNFCCC in 2011, the Maldives initiated its first major NAPA. After the Indian Ocean tsunami of 2004, the Disaster Management Act (2006) was enacted. It provides legal background for creating the National Disaster Management Council. Further, the National Disaster Management Centre was established in 2005 to coordinate response, recovery, and reconstruction efforts with support from the National Disaster Management Authority. The government of the Maldives also endorsed the world's first Strategic National Action Plan (SNAP) in 2009, which effectively integrates DRR and CCA.

Climate Change Advisory Council (CCAC) was created in 2009 and further developed the National Adaptation Programme of Action (NAPA) of 2006 with support from 
the Global Environment Facility (GEF) and UNDP. The National Planning Council (NPC) and the CCAC are other principal bodies that supervise climate change-related projects in the country. The focus of the NAPA has since been to identify the urgent and immediate needs of the country for addressing the impact of climate change and to present a coherent framework for CCA (MEE 2011).

\subsection{Nepal}

A CCA and DRR initiatives began simultaneously in Nepal, especially after the adoption of the HFA (Uprety 2009). Prior to 1982 , a makeshift approach to disaster response was in place until it was institutionalized through the enactment of the National Calamity (Relief) Act of 1982 (MoHA, GoN 2009; MoE, GoN 2011). The act established various bodies and defined the responsibilities of these institutions for disaster management at different levels of the administrative structure. The then Ministry of Home Affairs was endowed with responsibility for DRRrelated work. Nepal adopted a National Strategy for Disaster Risk Management (NSDRM) in 2010 and has initiated several flagship programs under the strategy.

The Ministry of Environment (MoE) has been endowed with the task of advising on issues relating to climate change. In line with national and international commitments, Nepal has accomplished various climate change initiatives, such as the 2030 Agenda for Sustainable Development, Millennium Development Goals, and the NAPA of 2009. A Climate Change Council was created in 2009 to provide policy and guidance to ensure overall coordination on climate change-related issues.

\subsection{Pakistan}

As with global developments, a parallel but disconnected evolution of DRR and CCA was evident in Pakistan (NDMA 2007, 2013). Pakistan took early action in creating a legal framework for managing disasters with the enactment of the West Pakistan National Calamities Act of 1958. After the 2005 Muzaffarabad earthquake, it came up with a new National Disaster Management Ordinance in 2006, which subsequently became the National Disaster Management Act of 2010. The national disaster management system now encompasses the National Disaster Management Commission (NDMC), with the National Disaster Management Authority (NDMA) as the focal point for disaster management at the federal level. The NDMA provides technical guidelines to stakeholders and advice on developing policies and plans to the NDMC. In 2011, the NDMA was transferred within the then Ministry of National Disaster Management before being renamed as the world's first full-fledged National Ministry of Climate Change in 2012.

Pakistan's environmental policy and CCA framework are based largely on the Pakistan Environmental Protection Act (PEPA) of 1997, which envisages two principle responsibilities: setting up the institutions and regulating environmental concerns. Since the adoption of the UNFCCC, several attempts have been made to develop an appropriate CCA framework. The most notable creation was the Cabinet Committee on Climate Change in 1995. In 2005, it was converted to the Prime Minister's Committee on Climate Change (PMCCC), forming the apex body for institutionalized mechanization of CCA. Further, a Clean Development Mechanism (CDM) has been activated since 2006 to give technical and policy-level support to all stakeholders. Planning and policy initiatives undertaken so far by the government include the National Conservation Strategy (NCS) of 1992, the Forestry Sector Master Plan, the NCS Plan of Action, and the National Environmental Action Plan (NEAP) of 2001. Despite some setbacks in evolving a national framework for climate change embedded in its Vision 2030, Pakistan successfully came out with a historical National Climate Change Policy in 2011.

\subsection{Sri Lanka}

Sri Lanka has been unique in evolving its institutional arrangement for disaster management. After ratifying the UNFCCC in 1994 and establishing a Disaster Management Centre (DMC) under the Ministry of Social Services in 1996, Sri Lanka has been developing its policies and plans for responding to DRR actions (MoDM 2005). After passing through several ministries, the disaster management sector has finally been housed within the Ministry of Disaster Management. Following the enactment of the Disaster Management Act in 2005, the National Council for Disaster Management (NCDM) and the DMC under the NCDM were established as apex bodies for planning, coordinating, and implementing responses to certain natural hazard-induced and other disasters.

After the ratification of the UNFCCC, the Sri Lankan Ministry of Environment and National Resource (MNER) became responsible for climate change-related activities. A National Environmental Action Plan (NEAP) has been in place since 1992, followed by the National Climate Change Plan, which provides guidance to stakeholders for addressing the adverse impacts of climate change. In 2008, the then Ministry of Environment set up a Climate Change Secretariat (CCS), which is currently under the Ministry of Mahaweli Development and Environment. With an aim of creating a clean development mechanism, Sri Lanka has created a National Climate Change Policy (NCCP) that 
articulates the guiding principles for action at the national, sectoral, and local levels. In 2010, the Sri Lankan government further adopted the National Climate Change Adaptation Strategy for 2011-2016, a framework for prioritizing action and investment for climate change-related sectors.

\section{Initiatives for Interlinking Disaster Risk Reduction and Climate Change Adaptation Over South Asia}

In the following section, institutional mechanisms to address DRR and CCA over different South Asian countries with initiatives to interlink DRR and CCA were briefed, considering adopted methodologies, salient features, and loopholes.

\subsection{Method for Developing Project Inventory}

Initially, the evolution of institutional setup for DRR and CCA and initiatives for interlinking DRR and CCA in the form of projects and programs across the SAARC member countries have been reviewed to identify the gaps and key challenges. The review has been made considering the information available in the public domain and subsequently by the desk-based literature review, expert interviews, and by using questionnaire survey. Documents based on review of reports, minutes, lectures, case studies, projects, and literature on DRR and CCA from various sources, including SAARC member states have been thoroughly analyzed to explore the promising areas of regional cooperation. A total of 371 projects and cases that were relevant to CCA and/or DRR were considered, with at least one project or case study from every member state (Table 2). The developed inventory was diverse in nature in terms of location, scale, sectoral focus, and strategic importance and ranged from community-based efforts to regional- and national-level programs. All the projects were reviewed for their objectives, nodal agencies, target population, methodologies, and expected/derived outcome, and further classified into individual sector (like natural resources, health, and so on) and their corresponding funding agencies (Table 3) to explore possible regional cooperation. The complete list of all the projects with details may be found in UNISDR/SDMC (2014).

After completing the literature review, we have conducted several interviews with disaster and climate change experts from government/United Nations/nongovernmental organization officials, and academics from the SAARC member states and other part of the world to identify the key challenges and issues in the existing policy and planning from a regional perspective. Accordingly, 16 interviews were conducted with disaster and climate change experts of SAARC member states. Additionally, two focused workshop with 20-25 participants in each were also conducted to discuss the findings from the literature review and interviews. All such information was analyzed to understand the detailed modalities of adopting DRR and CCA for the benefit of SAARC member states as per the Thimphu Statement. Finally, a consultation workshop among the experts of SAARC member states was organized during 29-31 August 2013 at Banaras Hindu University, Varanasi to discuss the key challenges and ways forward, which may serve as an efficient guide for policy planners and practitioners.

\subsection{Salient Features of Projects Interlinking Disaster Risk Reduction and Climate Change Adaptation}

Table 2 reveals that out of 28 projects initiated in Afghanistan, 21 target management of natural resources (agriculture, water, land, biodiversity, forestry, and coastal and wetland areas) while the least targeted sector was health. Climate change adaptation and DRR projects at both the national and the regional levels stand at a total count of 371 (National: 255; regional: 116). Meta-analysis of the projects on a national scale, completed or ongoing, reveals that among the South Asian states, Bangladesh (21.0\% share), India $(20.7 \%)$, and Bhutan $(20.7 \%)$ were proactive in implementing such projects. In contrast, Pakistan's share of such projects is minimum (2.8\%). Projects in natural resources management, including agriculture, water, land, biodiversity, forestry, and coastal and wetland areas make up $61 \%$ of all projects, while health $(2 \%)$ and communication $(2 \%)$ represent the most neglected sectors. Among the member states, projects in natural resources management are recorded as largest in India (approximately 13\%) and smallest in Pakistan (approximately 2\%). In terms of sectors, meta-analysis identified two facts: first, DRR is the most important among all the sectors; and second, Bangladesh leads the rest of the member states, with $6 \%$ of its DRR-based projects with respect to the total number of projects. Conclusively, Bangladesh holds the highest count of DRR including CCA projects implemented or yet to be implemented, whether overall or sector-based projects.

The numbers of projects for augmenting measures to integrate the process of DRR and CCA were highly deficient. This suggests a need to step up such efforts in the SAARC region and to formulate and execute more such projects for the benefit of the people. Further, United Nations organizations followed by national agencies of the respective countries have funded the majority of the implemented projects (Table 3). There are a similar number of activities by regional inter-governmental 
Table 2 Climate change adaptation (CCA) and disaster risk reduction (DRR) related sector-wise projects completed/ongoing in the South Asian Association for Regional Cooperation (SAARC) member states Source: UNISDR/SDMC (2014)

\begin{tabular}{|c|c|c|c|c|c|c|c|c|}
\hline \multirow[t]{2}{*}{ SAARC member states } & \multicolumn{7}{|c|}{ Sector-wise projects } & \multirow{2}{*}{$\begin{array}{l}\text { Total number } \\
\text { of projects }\end{array}$} \\
\hline & $\begin{array}{l}\text { Natural } \\
\text { resources }\end{array}$ & $\begin{array}{l}\text { Rural/urban } \\
\text { development }\end{array}$ & Health & Energy & Society & Communication & $\begin{array}{l}\text { DRM } \\
\text { flood/drought }\end{array}$ & \\
\hline Afghanistan & 21 & - & 1 & - & 2 & 1 & 3 & 28 \\
\hline Bangladesh & 27 & 2 & 1 & - & 9 & - & 15 & 54 \\
\hline Bhutan & 32 & 2 & 1 & 6 & 2 & - & 10 & 53 \\
\hline India & 33 & 2 & - & 1 & 5 & 1 & 10 & 53 \\
\hline Maldives & 16 & - & 1 & 1 & 5 & 1 & 4 & 28 \\
\hline Nepal & 13 & - & - & - & - & 1 & 7 & 21 \\
\hline Pakistan & 5 & - & - & - & 1 & - & 2 & 8 \\
\hline Sri Lanka & 8 & - & - & - & - & - & 2 & 10 \\
\hline $\begin{array}{l}\text { Regional CCA and DRR } \\
\text { Total }\end{array}$ & \multicolumn{8}{|c|}{$\begin{array}{l}\text { CCA Projects }(26)+\text { DRR Projects }(90)=\text { Total Regional Projects }(116) \\
(255+116) 371\end{array}$} \\
\hline
\end{tabular}

Natural resources include agriculture, water, land, biodiversity, forestry, coastal land, and wetland

$D R M$ disaster risk management

organizations, United Nations agencies, and multilateral and bilateral funding institutions, with the GFDRR (Global Facility for Disaster Reduction and Recovery) having the highest number of regional activities, followed by the ASEAN (Association of Southeast Asian Nations), ADB (Asian Development Bank), and SOPAC (Pacific Islands Applied Geoscience Commission). These multilateral and bilateral funding institutions and United Nations agencies have funded most activities related to climate risks. Differentiation between DRR and CCA projects was found to be extremely challenging and proving CCA as a subset of DRR as many of the projects and programs have the same domains; multiple sources of funding; and complex terms, strategies, locations, and impacts. These issues made comparisons among the cases extremely difficult. However, it appears that the portfolio of DRR including CCA activities in the region has expanded considerably. The sectors now include areas such as improving forecasting capacity, improving the supplies and efficiency of the irrigation sector, and adaptation measures in urban and rural sectors.

\subsection{Identified Challenges and Possible Ways Forward}

Meta-analysis of the institutional setup for DRR and CCA within the South Asian region revealed a lack of coordination and awareness among the nodal agencies, which critically limits their proper functioning. In most cases, stand-alone adaptation and disaster reduction policies were found to exist and DRR including CCA policies seemed extremely challenging due to the involvement of multiple institutions within similar kind of projects. In certain cases, duplication or even triplication in the execution of similar projects was identified, which often hindered the pace of effective execution in terms of both economy and benefit to the people. A lack of coordination also implies an excessive budgetary burden in executing similar types of projects and plans by different institutions and agencies. It was recognized that institutional development among SAARC member states to address all environmental hazards (DRR domain) and climate change-influenced environmental hazards (CCA domain) has evolved independently with minimum linkages.

One example is the case of Bangladesh, where geographic location and river morphology significantly contribute to all environmental hazards while uneven rainfall and earthquakes add to the susceptibility of the region to various form of hazards. Recently the effects of climate change have been more visible in terms of uneven distribution of rainfall and with increased frequency of tropical cyclones. In 2003, the Bangladesh MoFDM launched the Comprehensive Disaster Management Programme (CDMP) while in 2010, the Bangladesh government approved the National Plan for Disaster Management (NPDM), 2010-2015. The MoEF is the nodal agency to address CCA over Bangladesh, which has prepared the NAPA in 2005, updated it in 2009, and has the Bangladesh Climate Change Strategy and Action Plan (BCCSAP) in 2009. The MoFDM, now renamed as Ministry of Disaster and Relief (MoDMR) has the responsibility for addressing disaster management efforts across the nation. However, the MoDMR and the MoEF lack coordination of DRR including CCA policies, programs, and projects, while the scope for integration is plenty. According to Shamsuddoha et al. (2013), the existing National Disaster Management 


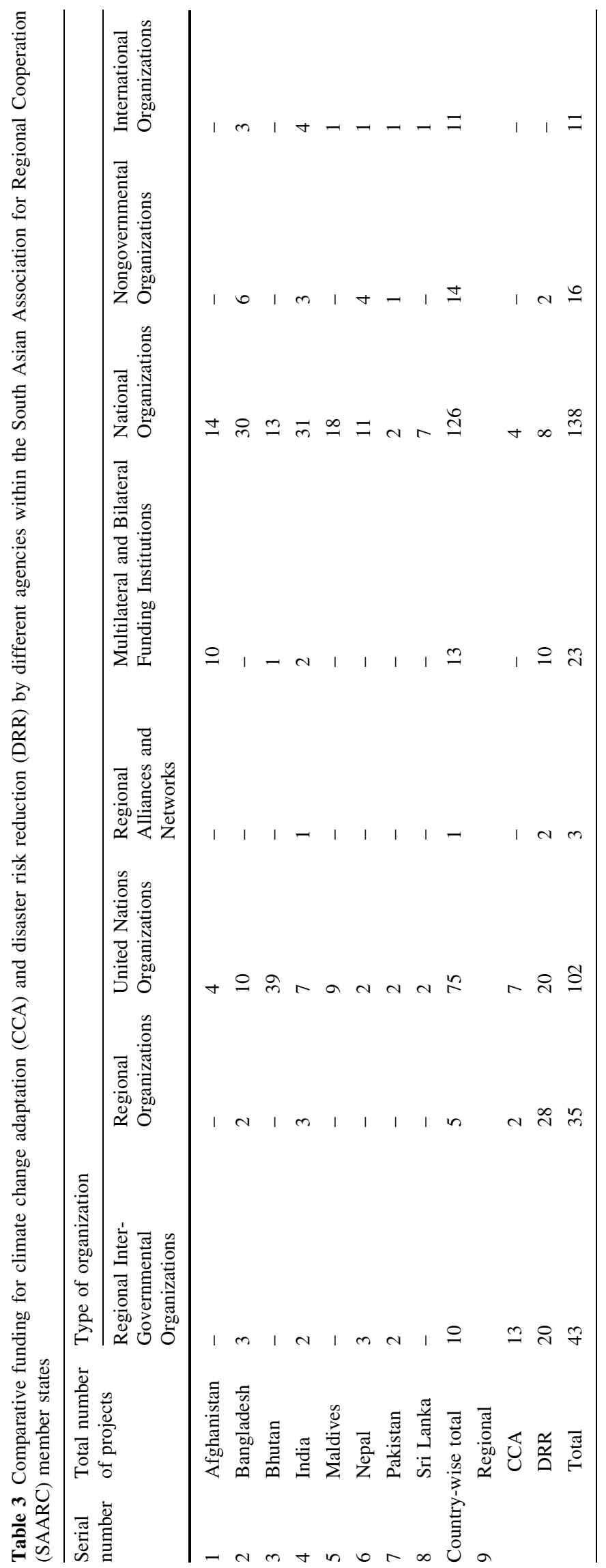


Council and National Environment Committee should coordinate and provide specific guidelines to relevant authorities for better DRR including CCA approaches. Similar evidence is also found in India where MoEF manages CCA while DRR comes under the purview of the Ministry of Home Affairs (MHA). Different ministries related to water resources, agriculture, health, social welfare, and space are an integral part of both CCA and DRR but they share different interfaces with the nodal authorities.

The entire South Asian region faces several challenges in addressing DRR including CCA in terms of magnitude, scale, dedicated funding, and lack of institutional mechanisms for sharing knowledge and technology. Therefore, member states need to develop coordinated programs to address such intricate issues at both the national and local levels. Some of the specific challenges and issues are as follows.

\section{(1) Variability in spatiotemporal scale}

The domain in which CCA has primarily been implemented is on a global, regional, or national scale, while there is a need to integrate CCA on a local scale. There is some evidence of CCA implementation on a local scale, but such actions are limited in number. The principal reasons for these limited applications are unavailability of projected climate information on a smaller scale due to lack of proper computational facilities, scientific complexity, and unavailability of local conditions. In contrast, DRR is practised in specific regions and localities where disasters usually occur (on a meso- or local/microscale). The climate change communities function on global or regional climate models and predict long-term global and regional climate scenarios. The DRR community, in contrast, focuses primarily on local vulnerabilities and risks of specific area, hazards, and groups of people potentially or actually affected. Thus, the difficulties that DRR and CCA managers usually face are lack of local and downscaled data for climatic conditions.

\section{(2) Diverse institutional structures and functional challenges}

The existing institutional arrangements for DRR and CCA at the regional, national, and subnational levels within the member states are not following the DRR including CCA approach to the extent of harnessing maximum benefits. Although different nations have diverse challenges and contexts to address DRR and CCA, for a region like South Asia, where disaster and climate change impacts are often cross-boundary, there is an urgent need to integrate different institutions that address DRR including CCA issues over the region. Over South Asia, several parallel institutions function to address DRR and CCA within different member states. In most of the cases, these institutions lack coherence and coordination in addressing DRR and CCA issues, more commonly for those having similar boundaries, and therefore create structural barriers. Further, as institutional arrangements for both DRR and CCA evolved independently, in most instances, DRR structures have backup from legislation, institutions, policy guidelines, and financial mechanisms, while legal instruments to address CCA are extremely limited among most of the countries.

The DRR structures in most of the member states of the SAARC region have a highly evolved and institutionalized setup that has its presence in policies, legislation, government orders, and functionality at all levels of administration (national to local) and therefore, can serve as a good platform for the CCA interventions to initiate at the national, regional, and local levels. In most SAARC countries, CCA issues have been managed by the environment and/or climate change, science and technology ministries in coordination with meteorological department, whereas DRR lies within the purview of the ministry of home, defence, relief, and national security. There is a scope of DRR including CCA in different countries through the common stakeholders and its parallel yet similar interfaces within the two structures. However, the integration should be both horizontal and vertical, in order to ensure proper functioning and improved communication among the institutions. A mechanism is therefore required to put in place within individual countries as well as for the region as a whole, for ensuring complete policies, plans, and programs undertaken for DRR including CCA.

\section{(3) Missing links in policies}

Across South Asia, planning, policies, and programs for DRR and CCA have taken place in isolation without sharing their respective aims, objectives, knowledge, and methodologies. Despite having multiple common attributes, there is limited evidence of DRR including CCA in planning and policies. Further, the approaches to manage disaster risks are still more of a reactive emergency management type while effective implementations of CCA require a lot of concentrated efforts. Therefore, it appears to be a critical disconnection between policies for CCA and DRR over the region, which are often regulated by different departments with little or no positive interactions.

\section{(4) Lack of knowledge sharing}

The SAARC member states lack an appropriate platform for sharing information and knowledge on progress made in CCA and DRR related issues. Important socioeconomic data, changing scenarios for regional vulnerability, and suitable adaptation strategies are not available in any one place. Efforts have been made to establish a SAARC 


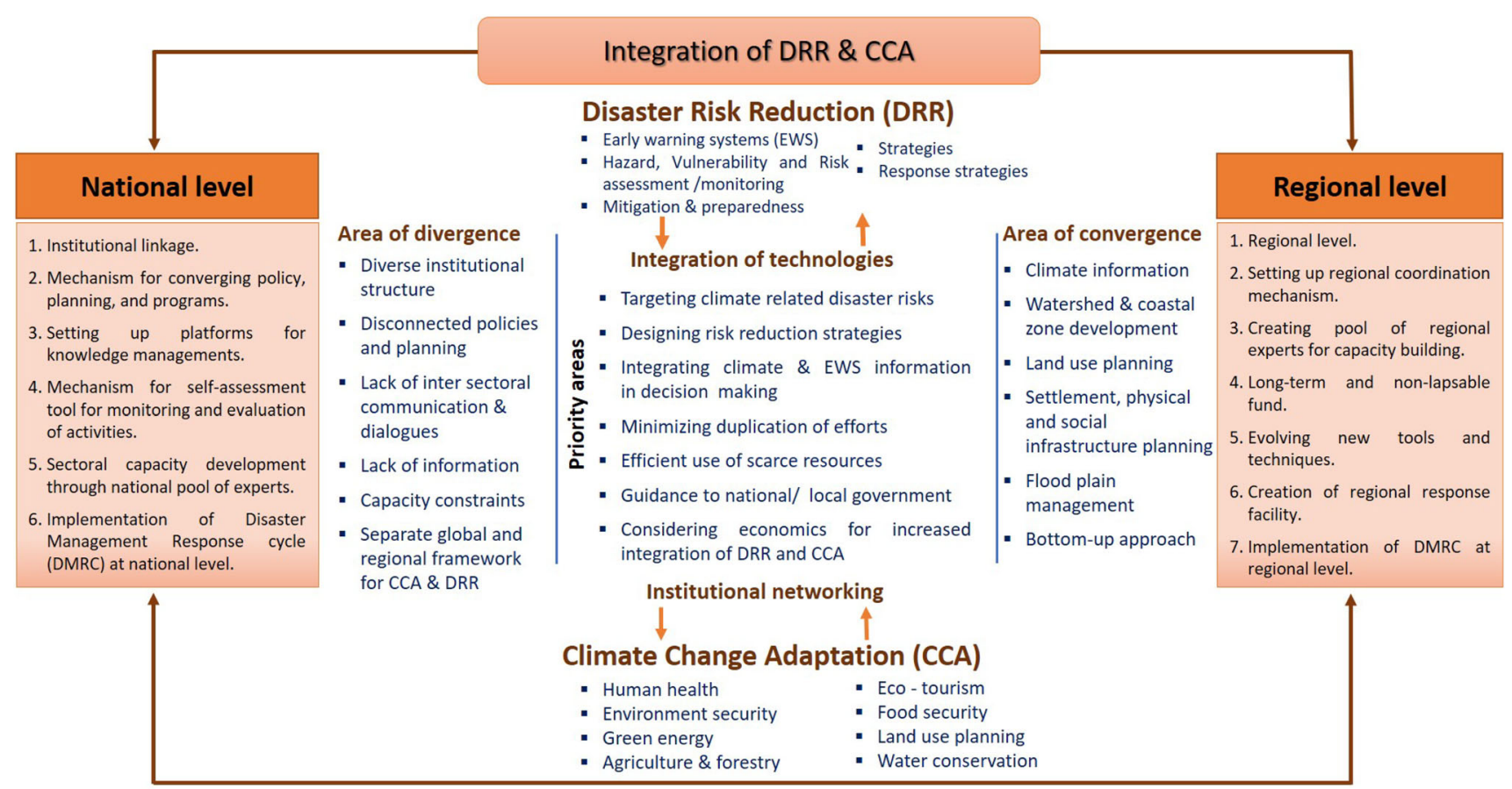

Fig. 2 Schematic diagram showing a holistic approach for integrating disaster risk reduction (DRR) with climate change adaptation (CCA) over the South Asian region. Source: Modified from Dhar (2010)

Disaster Management Centre that can provide advices and facilitate capacity-building services, including strategic learning, training, and research for DRR, to SAARC member states.

\section{(5) Lack of funding mechanisms}

Promotion and execution of adequate DRR including CCA plans require long-term financial support and consistent monitoring. The United Nations, intergovernmental, regional, multilateral, and bilateral cooperation initiatives, and national agencies have been funding various projects related to DRR including CCA within South Asia. However, there is no mechanism in place yet to avoid duplication and to ensure better coordination among projects.

\section{(6) Lack of coherence in project implementation}

A review of various projects and case studies revealed a lack of coherence in project implementation. In most cases, the implemented projects were diverse in nature, scale, and sectoral focus with different strategies. Therefore, in most cases, individual attempts failed to deliver the targeted objectives.

\section{Converging the Divergence of Disaster Risk Reduction and Climate Change Adaptation Over South Asia}

Both DRR and CCA have the objective of reducing factors that contribute to specific risks while ensuring sustainability in socioeconomic development. Conventionally, CCA tackles various facets of the impact of environmental degradation in the domains of water, agriculture, health, and infrastructure with the development of new tools for early warning systems. These are the areas in which measures of integration must be considered (Fig. 2). Within the purview of DRR, several mitigation and prevention measures can offset the potential of any hazard with approaches similarly taken under CCA. Such similarity may potentially be in terms of their nature, content, and approaches, which are employed to reduce the adverse effects.

While formulating a policy to develop an institution for addressing DRR including CCA, the current approaches remain in their respective silos. The major challenge, therefore, is to create commonality among the practices and operating procedures in the respective fields of CCA and DRR. Figure 2 compares the methodological differences between the frameworks. Parallels may also be drawn in the shifting emphasis on both types of policy action since 1985 . As a response to climate change, CCA was well recognized in early international agreements. The 
emphasis was on facilitating adaptation measures throughout South Asia while the funds needed to finance the adaptation processes were made available by various international treaties and conventions. A similar shift of focus from relief and response to preparedness and vulnerability reduction was also evident for DRR policies. Recently, initiatives for extending regional cooperation in responding to climate change and managing disasters have been taken under the HFA, Sendai Framework, National Communication (NATCOM), NAPAs, and SNAP and through the establishment of regional centers. Disaster risk reduction including CCA calls for actions in identifying all such areas that facilitate convergence among various approaches to CCA and DRR. Projects related to drought risk mitigation, land use planning in areas prone to climaterelated environmental hazards, integrated coastal zone management, integrated watershed development, and capacity building are those with the most potential for effective DRR including CCA also achieved. These DRR including CCA measures need to be recognized as good practises by other member states through regional cooperation.

\section{Conclusion}

In view of the evidences on existing status and scope of integrating disaster risk reduction including climate change adaptation in various development projects, policies, and planning across South Asia, it has been learned that there are some fundamental and implemental constrains that necessitate priority attentions. We therefore conclude few priorities that require agreement and development within the South Asia partner states, governmental and international agencies, and disaster/climate experts, and offer some practical means to achieve these.

To address the DRR including CCA over South Asia, top priorities should be to establish institutional linkages at both the national and regional levels by removing structural barriers. Emphasis should be given to establishing integration among various institutions both horizontally and vertically. A mechanism for convergence of policies, planning, and programs should also be prioritized. The SAARC member states should put in place a framework for ensuring complete integration of policies, plans, and programs undertaken for DRR including CCA within individual countries and for the entire region. There is also a need to establish a platform for knowledge sharing, like a climate change knowledge management center parallel to the SAARC Disaster Management Centre (SDMC) or a division within the SDMC to facilitate sharing knowledge and information, conducting regional research, and replicating good practices among SAARC member states. To leverage the capacity of member states, a regional response facility should be created under the SDMC to facilitate quick mobilization and deployment of critical resources.

A precise and efficient mechanism for monitoring and evaluating implemented projects is also required. Such mechanism is necessary for maintaining standard among all the implemented projects. Guidance notes on compliance, quality control, and evaluation criteria on different scales may also be developed to assist both policymakers and practitioners. Additionally, a non-lapsable SAARC fund should be constituted with development of new tools and techniques to support the DRR including CCA by the member states. A regional coordination mechanism for various agencies in relevant sectors such as agriculture, water resources, and health is necessary for member states to manage common resources.

We also felt the necessity to set up a roster of regional and international disaster/climate experts within the South Asian member states. Various SAARC member states have developed considerable expertise (for example, scientific, technical, administrative, and search and rescue) in various aspects of DRR and CCA. Such expertise may well be utilized and shared for the common good across the region. The SAARC Secretariat should create and maintain a panel of experts from the member states that may be utilized as and when needed by individual member states. We also strongly advocate for constituting a platform for corporate engagement by means of engaging chambers of industry and commerce for all member states to facilitate partnerships in efficient implementation of DRR including CCA.

Acknowledgements The authors are thankful to the SAARC Disaster Management Centre, New Delhi; the United Nations International Strategy for Disaster Reduction (UNISDR); and the Climate Change Programme, Department of Science and Technology, New Delhi, India for support to this study. However, all the views expressed in this article are solely of the authors. The authors also highly appreciate the Associate Editor Professor Ilan Kelman and anonymous reviewers for their professional and pertinent comments, which were greatly helpful in improving the manuscript.

Open Access This article is distributed under the terms of the Creative Commons Attribution 4.0 International License (http://crea tivecommons.org/licenses/by/4.0/), which permits unrestricted use, distribution, and reproduction in any medium, provided you give appropriate credit to the original author(s) and the source, provide a link to the Creative Commons license, and indicate if changes were made.

\section{References}

Alexander, B., L.J. Cox, and J. Mochizuki. 2013. Integrated risk identification, analysis, and assessment: A dynamic household economy analysis methodology and example. International Journal of Disaster Risk Science 4(2): 77-88. 
Banwell, N., S. Rutherford, B. Mackey, and C. Chu. 2018. Towards improved linkage of disaster risk reduction and climate change adaptation in health: A review. International Journal of Environmental Research and Public Health 15(4): 793.

Bhatt, D., R.K. Mall, and T. Banerjee. 2015. Climate change, climate extremes and disaster risk reduction. Natural Hazards 78(1): $775-778$.

Brewer, G., J. von Meding, and G. Forino. 2018. Governing the integration of climate change adaptation into disaster risk reduction: Insights from two Australian local governments. In Governance of risk, hazards and disasters, ed. G. Forino, S. Bonati, and L. Maria, 101-116. Abingdon: Routledge.

Dhar, C.P.G. 2010. Integrating disaster risk reduction with climate change adaptation-Recent initiatives in South Asia. Disaster and Development 4(1): 159-183.

Dias, N., D. Amaratunga, and R. Haigh. 2018. Challenges associated with integrating CCA and DRR in the UK-A review on the existing legal and policy background. Procedia Engineering 212: 978-985.

EM-DAT (Emergency Events Database). 2016. The international disaster database, natural disasters trends. Brussels: Belgium.

Gaiha, R., and G. Hill. 2010. Natural disaster in South Asia. In Routledge handbook of South Asian economics, ed. R. Jha, 109-128. Abingdon: Routledge.

GIRA (Government of the Islamic Republic of Afghanistan). 2005. Afghanistan national development strategy: An interim strategy for security, governance, economic growth \& poverty reduction. Kabul: GIRA.

Gupta, S., and M. Murlikrishna. 2010. South Asia disaster risk management programme: Synthesis report on SAR countries disaster risks. Noida: RMSI Private Limited.

Hasan, Z., S. Akhter, S. Ahmed, and A. Kabir. 2013. Challenges of integrating disaster risk management and climate change adaptation policies at the national level: Bangladesh as a case. Global Journal of Human-Social Science: (B) Geography, Geo-Sciences Environmental Science \& Disaster Management 13(4): 55-64.

IPCC (Intergovernmental Panel on Climate Change). 2013. Climate change 2013: The physical science basis. Contribution of Working Group I to the Fifth Assessment Report of the Intergovernmental Panel on Climate Change, ed. T.F. Stocker, D. Qin, G.-K. Plattner, M. Tignor, S.K. Allen, J. Boschung, A. Nauels, Y. Xia, et al. Cambridge: Cambridge University Press.

Kelman, I., and J.C. Gaillard. 2008. Placing climate change within disaster risk reduction. Disaster Advances 1(3): 3-5.

Kelman, I., J. Mercer, and J.C. Gaillard. 2017. Editorial introduction to this handbook: Why act on disaster risk reduction including climate change adaptation. In The Routledge handbook of disaster risk reduction including climate change adaptation, ed. I. Kelman, J. Mercer, and J.C. Gaillard, 3-6. Abingdon: Routledge.

Kelman, I., J. Mercer, and J.J. West. 2009. Integrating indigenous and scientific knowledge for community based climate change adaptation. Participatory Learning and Action 60: 41-53.

Mall, R.K., S.D. Attri, and S. Kumar. 2011a. Extreme weather events and climate change policy in India. Journal of South Asian Disaster Studies 4(2): 37-56.

Mall, R.K., A. Gupta, R. Singh, R.S. Singh, and L.S. Rathore. 2006. Water resources and climate change: An Indian perspective. Current Science 90(12): 1610-1626.

Mall, R.K., R. Kumar, and R. Bhatla. 2011b. Climate change and disaster in India. Journal of South Asian Disaster Studies 4(1): 27-76.

Mall, R.K., and R.K. Srivastava. 2012. Sustainable flood management in changing climate. In Flood risk management in South Asia, ed. O.P. Mishra, M. Ghatak, and A. Kamal, 49-66. New Delhi: SAARC Disaster Management Centre.
MEE (Ministry of Environment and Energy). 2011. Strategic national action plan for disaster risk reduction and climate change adaptation 2010-2020. Male, Maldives: MEE.

Mercer, J., I. Kelman, F. do Rosario, A. de Deus de Jesus Lima, A. da Silva, A.M. Beloff, and A. McClean. 2014. Nation-building policies in Timor-Leste: Disaster risk reduction, including climate change adaptation. Disasters 38(4): 690-718.

MHA (Ministry of Home Affairs). 2011. Disaster management in India. New Delhi: MHA.

MoDM (Ministry of Disaster Management). 2005. Towards a safer Sri Lanka: Road map for disaster risk management. Colombo: MoDM.

MoE, GoN (Ministry of Environment, Government of Nepal). 2011. Status of climate change in Nepal. Kathmandu: MoE, Government of Nepal.

MoEF (Ministry of Environment and Forests). 2012. India second national communication to the United Nations framework convention on climate change. New Delhi: MoEF.

MoEF, GoB (Ministry of Environment and Forests, Government of the People's Republic of Bangladesh). 2009. National adaptation programme of action (NAPA). Dhaka: MoEF, Government of the People's Republic of Bangladesh.

MoEF, GoB (Ministry of Environment and Forests, Government of the People's Republic of Bangladesh). 2012. Introduction to Ministry of Environment and Forest. Dhaka: MoEF, Government of the People's Republic of Bangladesh.

MoEFCC (Ministry of Environment, Forest and Climate Change). 2008. National action plan on climate change. New Delhi: MoEFCC.

MoHA, GoN (Ministry of Home Affairs, Government of Nepal). 2009. National strategy for disaster risk management. 2009. Kathmandu: MoHA, Government of Nepal.

NDMA (National Disaster Management Authority). 2007. National disaster risk management framework Pakistan. Islamabad: NDMA.

NDMA (National Disaster Management Authority). 2013. National disaster risk reduction policy. Islamabad: NDMA.

O'Keefe, P., K. Westgate, and B. Wisner. 1976. Taking the naturalness out of natural disasters. Nature 260(5552): 566-567.

Raza, T. 2018. Localizing disaster risk reduction and climate change adaptation in planners' and decision makers' agenda: Technical comprehensive model, Quezon City, Philippines. Procedia Engineering 212: 1311-1318.

SAARC (South Asian Association for Regional Cooperation). 2008. Regional cooperation on climate change adaptation and disaster risk reduction in South Asia: Road map. SAARC Workshop on Climate Change and Disasters: Emerging Trends and Future Strategies. Kathmandu, Nepal, 168-182.

Seidler, R., K. Dietrich, S. Schweizer, K.S. Bawa, S. Chopde, F. Zaman, A. Sharma, S. Bhattacharya, L.P. Devkota, and S. Khaling. 2018. Progress on integrating climate change adaptation and disaster risk reduction for sustainable development pathways in South Asia: Evidence from six research projects. International Journal of Disaster Risk Reduction 31: 92-101.

Shamsuddoha, M., E. Roberts, A. Hasemann, and S. Roddick. 2013. Establishing links between disaster risk reduction and climate change adaptation in the context of loss and damage: Policies and approaches in Bangladesh. Dhaka: Department for International Development.

UNDP (United Nations Development Programme). 2013. Human development report 2013: The rise of south-Human progress in diverse world. New York: UNDP.

UNESCAP (United Nations Economic and Social Commission for Asia and the Pacific). 2016. Asia-Pacific disaster report 2015: Disasters without borders-Regional resilience for sustainable development. Bangkok: UNESCAP. 
UNFCCC (United Nations Framework Convention on Climate Change). 2008. In Proceedings of the 13th Conference of the Parties, 3-15 December 2007, Bali: United Nations.

UNISDR (United Nations International Strategy for Disaster Reduction). 2011. Global assessment report on disaster risk reduction: Revealing risk, redefining development-Summary and main findings. Geneva: United Nations.

UNISDR (United Nations International Strategy for Disaster Reduction). 2015. Sendai framework for disaster risk reduction 2015-2030. Geneva: United Nations.

United Nations. 2018. List of least developed countries (as of March 2018). Geneva: United Nations Committee for Development Policy Development Policy and Analysis Division Department of Economic and Social Affairs.

UNISDR/SDMC (United Nations International Strategy for Disaster Reduction/SAARC Disaster Management Centre). 2014. Integration of disaster risk reduction and climate change adaptation in SAARC region: Implementation of the Thimphu statement of climate change-A comprehensive study of the policy, institutional landscape and resource allocation for disaster risk reduction and climate change adaptation in South Asia (Disaster prevention, preparedness \& management, linkages with CCA). New Delhi: SDMC.

Uprety, B.K. 2009. Climate change: Major initiatives and development in Nepal. The Initiation 3: 128-134.

Vij, S., R. Biesbroek, A. Groot, and K. Termeer. 2018. Changing climate policy paradigms in Bangladesh and Nepal. Environmental Science \& Policy 81: 77-85.

Xu, D., L. Peng, S. Liu, and X. Wang. 2018. Influences of risk perception and sense of place on landslide disaster preparedness in Southwestern China. International Journal of Disaster Risk Science 9(2): 167-180.

Zuccaro, G., and M.F. Leone. 2018. Building resilient cities: A simulation-based scenario assessment methodology for the integration of DRR and CCA in a multi-scale design perspective. Procedia Engineering 212: 871-878. 